\title{
EDITORIAL
}

\section{Learning technology and organisations: transformational impact?}

This collection of papers contributes to a wide and ongoing strand of interest in alternative learning technologies: how are digitally-enabled ways of working transforming organisations? In 'transformation' we look for radical change, rather than just doing the same at a different scale. And in organisations we centre on educational institutions - across the full range of schooling, training, further and higher education while recognising that conventional boundaries are increasingly broken as different kinds of organisations invest in digitally-enabled learning.

In assembling this edition of $A L T-J$, we asked those working in the field to think about a set of inter-related issues. How are the changing strategic needs of organisations affecting their technological requirements? What are the implementation and management challenges that organisations have faced in adopting new learning technologies? What has happened when organisations have had to integrate learning management systems and other, now-common, technologies? Looking ahead, what will be the learning technologies of the future?

The scope of the papers that follow shows how these issues are affecting all levels of education provision. Sangrà and González-Sanmamed are interested in primary and secondary schools, and de la Varre, Keane, and Irvin in the particular issues that online distance education raises for remote, rural schooling. Cochrane's study of provision using mobile devices - m-learning - is at the college level, although the implications are wider. Gosper, McNeill, Phillips, Preston, Woo, and Green tackle the challenges that new digital capabilities bring to the traditional university lecture. Their work is matched by Keppell, O'Dwyer, Lyon, and Childs's interest in new approaches to teaching in university-level distance education. Yaneske and Oates report on the use of new technologies in specialised postgraduate teaching and learning. And while Marshall's concern with models of organisational change is directed at higher education, his perspective can be applied to the dynamics of institutional transformation in education institutions at all levels.

The question of the effect of changing strategic needs on the technological requirements of organisations can be framed in terms of deepening quality. Quality is a famously elusive term. Here, we mean the challenge of responding to the new and changing needs of learners at all levels. The massive expansion of digital capacity and processing power from the early 1990s onwards has both changed the nature of work and widened the reach of opportunity. For people in almost any aspect of employment, digitally enabled systems are now commonplace and the ability to use them is a basic requirement of the job. Further, the accelerating rate of change in technology and process innovation means that there is a constant and continuing need to learn; the notion of being qualified for life at the beginning of a career is an anachronism. For those marginalised or excluded from employment, digital technologies offer opportunities that can overcome distance and the lack of resources. As a consequence, the 
structure, content and reach of any educational institution's curriculum are at the centre of its strategic position. Put another way, any college or university that assumes its curriculum and range of qualifications it offers are constants that can be taken for granted is likely to face acute strategic challenges.

Digital technologies have massively widened access to learning. Internet platforms, enhanced by real-time sound and video streaming, high-quality digital images and limitless volumes of text files, now offer a compelling alternative to the conventional classroom. Structured curriculum content is easily available online and, thanks to innovators such as MIT and the Open University, increasingly open to all. Social networking systems such as Facebook and YouTube provide for the informal interaction and peer-to-peer sharing that is an essential ingredient of beneficial learning experiences. Increasingly, new-generation mobile devices allow learning activities to take place anywhere within the reach of a digital network. These trends are reflected in studies in this collection. De la Varre, Keane, and Irvin's work with the use of information technologies in rural schools is a case study in widening and deepening education in challenging circumstances. They point out that rural US high schools face challenges such as isolation, lack of teachers, limited curricula, reduced funding, and consolidation. As rural populations decline, some of these exclusionary factors are becoming more pronounced. Gosper et al. argue that one factor driving students' enthusiasm for web-based lectures is that asynchronous forms of learning widen opportunities for combining work and study, suggesting in turn opportunities for widening participation beyond cohorts of students who can afford full-time study.

When coupled with the diminishing costs of both technology and connectivity, this extended reach means that well-established educational organisations can more easily expand into new areas, and that the barriers to entry into education provision for new competitors are falling away. It is often now the case that competition is limited more by government regulation of learner qualifications than by the requirements of provision. Several papers in this collection show how it is often learners who lead in the dynamics of organisational change that follows from these sorts of circumstance. In Gosper et al.'s study of web-based lectures in Australian universities, there is a clear distinction between students, who see in web-based lectures opportunities for flexibility, and lecturers, who are concerned that the loss of face-to-face contact will diminish the educational experience. De la Varre, Keane, and Irvin's work on online distance education in rural US schools shows that this interplay between teachers and students is often complex, as students work to adapt to the opportunities of new ways of learning. For its part, Cochrane's micro-study of the use of mobile technologies in specific courses shows how this has shaped communities of practice between learners, setting trajectories for future organisational change.

The second issue that we put in framing this call for papers follows from the strategic prioritisation of new learning technologies. What implementation and management challenges can follow? There is of course a massive literature on managing organisational change, some of which is applicable to educational institutions. Marshall's paper in this volume provides an insightful route into this field. Colleges and universities are notoriously complex and may be driven by sets of internal interests that are not necessarily aligned with the chosen strategic direction of the organisation's leadership. How well do innovators fare in advancing their arguments for change, and for the resources to bring change about? What enabled some organisations to lead in implementation, with appropriate management support, while others lag, with the sheer weight and friction of established ways of doing things 
taking the shine off even the brightest of strategies? Given that digitally-enabled learning and teaching technologies have been an aspect of growing importance in most educational organisations for some two decades, we should be in a position to learn from institutional histories.

Marshall's approach is to provide a perspective on different models of organisational change available to us. He argues that university culture and existing capability can constrain innovation and may determine the nature and extent of transformation. In the absence of strong leadership, technologies are simply used as vehicles to enable changes that are already intended or which reinforce the current identity. In a study that complements Marshall's work, Keppell et al. show that distributed leadership may facilitate institutional transformation. Their example is of a Teaching Fellowship scheme that encourages reflection, understanding, innovation and evaluating equity issues in blended learning.

An important subset of implementation and management challenges can best be flagged as the unintended and unanticipated consequences of the digital revolution in learning and teaching. For example, some of the mentors in de la Varre, Keane, and Irvin's study reported that learners were more reluctant to ask questions in on-line learning environments. And students in Yaneske and Oates's study of Voice Boards in a course for language-learners were sometimes inhibited when required to abandon the comparative safety of text-only communication. In addition to the unintended consequences highlighted in this collection of papers, there is the obvious problem of plagiarism. In the age of innocence that predated the burst of the first Internet bubble in the 1990s we envisaged a net citizenry thriving on open information and communication. Now, no education provider can afford to be without ubiquitous plagiarismdetection software to stay ahead of cheating by students, staff and the occasional college president. In addition, all digitally-enabled organisations have to deal with vast quantities of unwanted mail, ever-more sophisticated attempts at fraud, privacy violations and malicious attacks.

Our third question sought to probe a more specific issue of implementation. What happens when specialised learning management systems have to be integrated with other technologies? Almost all large organisations, as well as very many smaller ones, have lived through the transition from long-established systems of financial, payroll and human resources management to the comprehensive enterprise systems that are now commonplace. In colleges and universities, these generic systems have had to be integrated with more specialist learning management systems for student recruitment, admissions and management, the management of alumni networks and virtual learning environments. Some institutions have opted for single suppliers while others have chosen to mix and match, sometimes including Open Access systems. Almost all organisations will have encountered challenges of inter-operability. Almost all will have found that budgeted allocations are a fraction of the final and associated costs of implementation and required, downstream, upgrades. Many will have secretly yearned for simpler days of chalkboards and overhead projectors.

Several papers in this collection contribute to this set of issues, looking at the ways in which established technologies of learning and teaching are interacting with longerestablished approaches. Yaneske and Oates are concerned with digitally-enabled audio communication and the opportunity to introduce pitch, tone, emphasis and inflection into online language teaching. While this may be a return to some of the qualities of traditional, face-to-face teaching of languages, for contemporary learners it represents a departure from the norm of text-based digital communication. Their 
study is matched by Cochrane's analysis of a range of courses. Here, the interface is between mobile technologies and other technologies of teaching. Sangrà and González-Sanmamed show that when schools have seen information and communication technologies as an opportunity for innovation, there is greater improvement in teaching and learning. They argue that the effective integration of new learning management systems with established approaches therefore requires an emphasis on the teaching and learning processes themselves, rather than just on the interface between technology systems. Their conclusion is endorsed by Gosper et al.'s work in Australian universities. Here, the concern is that lecturers are lagging behind their students in seeing the potential of new learning technologies. The result can be that there is no inclination to look to the pedagogic opportunities that lie in the full integration of older and newer approaches to teaching and learning.

And, finally, what will the future bring? What will it mean for educational institutions if many of these enterprise systems are hosted by external partners, and there is no longer the need for large, in-house information technology departments? What are the implications - and opportunities - in a world in which all of our key data is in the Cloud? Is the openness of the Web already a memory, as increasing amounts of content are barricaded behind pay-walls and the Web begins to segment into membership groups? And is, perhaps, the one constant in our digitally-enabled world the unpredictability of the future?

The papers that follow do not answer any of these questions definitively. Indeed, it would be contrary to the boundless and explosive characteristics of contemporary, digitally-enabled knowledge to expect any collection of positions and research outcomes to be definitive. Rather, our contributors take aspects of the questions we have posed, toss them about and add to them, and reframe the issues in the light of specific circumstances and experiences. The overall outcome is more questions. And that is the nature of the digitally-enabled world of knowledge-making that we all inhabit.

Professor Martin Hall University of Salford, UK

Professor Mike Keppell

Charles Sturt University, Australia

Professor John Bourne The Sloan Consortium, USA 